\title{
Os usos do presente do indicativo: reflexões teóricas e proposta didática para um estudo contemporâneo da linguagem
}

DOI: http://dx.doi.org/10.21165/el.v50i1.2899

\section{Regislene Dias de Almeida'}

\section{Resumo}

O presente artigo traz uma reflexão teórica sobre os usos do presente do indicativo, levando em consideração o que os documentos oficiais norteadores do ensino apontam como práticas desejáveis para o ensino de gramática, na educação básica. Analisamos algumas abordagens desse tempo verbal em materiais didáticos e apresentamos uma proposta didática voltada ao estudo do presente do indicativo no ensino fundamental. A proposta didática apresentada pretende contribuir com o estudo do verbo, à medida que aproxima esse estudo das práticas linguísticas correntes. Os resultados apontam que, mesmo os documentos oficiais e os estudos acadêmicos indicando a necessidade de uma aprendizagem linguística mais próxima da realidade, com práticas que superem a descontextualização e a mera descrição da norma, essa abordagem ainda prevalece em muitos materiais e práticas pedagógicas.

Palavras-chaves: presente do indicativo; análise linguística; proposta didática.

1 Universidade de São Paulo (USP), São Paulo, São Paulo, Brasil; profregislene@gmail.com; https://orcid.org/0000-0002-0713-3821 


\title{
Present of the indicative usage: Theoretical reflections and a didactic proposal for a contemporary language study
}

\begin{abstract}
This article consists of a theoretical reflection on the present of the indicative usage. This article considers the desirable practices for grammar teaching in Basic Education as defined by official teaching guidelines. The author analyses some approaches on this verbal tense in didactic materials and then presents a didactic proposal for the study of the present of the indicative in Basic Education. The didactic proposal presented intends to contribute to the study of the verb, as it brings this study closer to everyday language practices. The results suggest that the decontextualization and simple description of the norm still prevail on many pedagogic materials and practices, despite official guidelines' and academic studies' demonstration of the need for linguistic learning closer to reality.
\end{abstract}

Keywords: present of the indicative; linguistic analysis; didactic proposal.

\section{Apresentação}

O estudo dos tempos, modos e aspectos verbais é um conteúdo corrente nas aulas de Língua Portuguesa, em diversos momentos da trajetória escolar. Hoje, com um foco maior nos anos finais do ensino fundamental, mais precisamente entre o $6^{\circ}$ e $7^{\circ}$ anos, o ensino e a aprendizagem desse conteúdo ainda guardam resquícios das práticas pedagógicas do início do século: a memorização de nomenclaturas, apresentação de modelos de conjugação e exemplos distantes de situações de uso.

Sabemos que os anseios para que o ensino de gramática aconteça de uma forma contextualizada, ancorado nas diversas práticas de linguagem que figuram na sociedade, aparecem nos documentos oficiais já há algum tempo. Desde o lançamento dos Parâmetros Curriculares Nacionais, os PCNs, em 1997, temos registradas orientações para que a aprendizagem linguística supere a descontextualização e a mera descrição da norma. Esses anseios se repetem no documento mais recente, que é a Base Nacional Comum Curricular, a BNCC, lançada em 2017, quando trata dos objetivos para o ensino de Língua Portuguesa, centrados na formação de sujeitos proficientes, tendo como escopo a perspectiva enunciativo-discursiva da linguagem. Dessa forma, a formação integral do indivíduo passa a ser prioritária e propõe a superação da fragmentação radicalmente disciplinar do conhecimento, por meio do estímulo à aplicação do que foi aprendido, na vida real.

Diante dessas necessidades, justifica-se o interesse pelo tema deste artigo. Considerando o verbo como uma categoria semântica essencial na produção dos discursos, o seu estudo, nas aulas de Língua Portuguesa, torna-se imprescindível para que nossos 
alunos se comportem como sujeitos autônomos linguisticamente, capazes de entender, interpretar e produzir seus próprios discursos, empregando as variedades e os efeitos de sentido que desejarem. Acreditamos que entendendo a gramática da língua, que é o mesmo que compreender o seu funcionamento nas diversas instâncias comunicativas, teremos um falante proficiente e atuante como ser social, uma vez que as nossas interações dependem, em grande parte, da linguagem verbal.

Neste trabalho, pretendemos apresentar o ensino dos tempos e modos verbais, mais especificamente do presente do indicativo, na forma como se encontra em uma das coleções didáticas de Língua Portuguesa, aprovada pelo PNLD 2020, e em algumas gramáticas didáticas contemporâneas, considerando sua abordagem teórica e a proposição de exercícios, quando houver. Em seguida, apresentamos algumas discussões científicas sobre o aspecto verbal, encontradas em Castilho (2019) e em Vargas (2010). Por fim, sugerimos uma proposta didática para aplicação no ensino fundamental, que objetiva superar algumas abordagens tradicionais e descontextualizadas, para o ensino desse tempo verbal.

\section{O presente do indicativo nos livros didáticos e gramáticas tradicionais}

O livro didático se apresenta aos professores como um importante instrumento de trabalho. Presos em rotinas exaustivas, com excessivo número de aulas e pouquíssimo tempo para estudo e preparação de materiais, a maioria dos docentes recorre aos exercícios propostos pelos livros, que se tornam uma alternativa bastante viável para uso em sala de aula, principalmente pelo fato de estarem disponíveis a todos os alunos.

Em coleções mais recentes, de livros de Língua Portuguesa, encontramos tentativas de aproximação do estudo da gramática com o texto. As unidades e capítulos geralmente são temáticos, organizando-se por gêneros textuais ou discursivos. Em alguns, relacionase o conteúdo gramatical com o gênero em estudo. É comum termos, em uma unidade cujo trabalho será com sequências opinativas e argumentativas, por exemplo, carta do leitor, debate regrado, artigo de opinião, dissertação escolar. Nesse mesmo capítulo, provavelmente, a abordagem do conteúdo gramatical será centrada em articuladores e modalizadores textuais, como estratégias para "ensinar" a argumentação.

O que ocorre, no entanto, é que mesmo vinculando tópicos de gramática à constituição dos gêneros, a relação entre a gramática do texto e o texto não se estabelece. Na maioria dos livros analisados, a abordagem do conteúdo gramatical aparece em seções separadas, no capítulo, com alguns exemplos recorrendo a frases soltas, retiradas ou não - dos textos apresentados anteriormente. Há pouca reflexão sobre o contexto discursivo ou sobre as diferenças de sentido em se utilizar esta ou aquela construção frasal, por exemplo. 
Na coleção Singular \& Plural, das autoras Laura de Figueiredo, Marisa Balthasar e Shirley Goulart (2019), há um compêndio, ao final do exemplar de cada ano, que conta com uma relação de modelos de conjugação verbal, lista de preposições e conjunções, advérbios e locuções adverbiais, sem qualquer menção às particularidades ou situações de uso.

Em relação ao estudo dos verbos, geralmente ele é encontrado nos exemplares de $6^{\circ} \mathrm{e}$ $7^{\circ}$ anos, sendo que, no $6^{\circ}$ ano, a ênfase recai sobre os aspectos morfológicos, dentro da parte dedicada ao estudo das classes de palavras e, no $7^{\circ}$, abordam-se aspectos mais relacionados à sintaxe, como sua centralidade na constituição dos predicados verbais e nominais.

Como exemplo, temos os livros de $6^{\circ}$ e $7^{\circ}$ anos, da coleção Português: conexão e uso, das autoras Dileta Delmanto e Laís B. de Carvalho (2018), aprovada pelo PNLD 2020. O exemplar de cada ano é composto por oito unidades e, em cada unidade, há uma seção intitulada "Reflexão sobre a língua" em que são apresentados tópicos gramaticais. No exemplar do $6^{\circ}$ ano, o estudo do verbo aparece na unidade 5 , logo após os estudos do substantivo (unidade 3 ) e do adjetivo (unidade 4). Nessa unidade, as autoras trazem definições sobre a classe de palavras (o que é o verbo, suas flexões em pessoa, número, tempos e modos) e exercícios relacionados a esses conceitos. Já no livro do $7^{\circ}$ ano, o estudo do verbo situa-se nas unidades 2 e 3, centrando-se nos usos dos tempos verbais, no modo indicativo.

Em relação aos exercícios que acompanham as explicações teóricas, são comuns aqueles que pedem ao aluno para identificar o tempo e modo verbais que estão sendo utilizados nos textos apresentados e que situações expressam. Como expectativa de resposta, espera-se que os alunos consigam identificar os tempos e modos, nomeandoos, e relacioná-los às definições que constam em "box explicativos". Trazemos como exemplo, aqui, a reprodução de algumas definições encontradas nas caixas explicativas do exemplar de $6^{\circ}$ ano, de Delmanto e Carvalho: a) "O uso do modo indicativo expressa fatos considerados reais, certos, verdadeiros" (DELMANTO; CARVALHO, 2018a, p. 168, grifo das autoras). b) "O uso do modo subjuntivo expressa fatos considerados duvidosos, incertos ou possíveis, mas não necessariamente verdadeiros" (DELMANTO; CARVALHO, 2018a, p. 169, grifo das autoras). c) "O uso do modo imperativo pode expressar ordem, pedido, proibição, convite ou recomendação, dependendo do contexto em que é utilizado" (DELMANTO; CARVALHO, 2018a, p. 170, grifo das autoras).

Percebemos que esses conceitos pretendem ser recuperados em exercícios que trazem um texto para estudo, acompanhado de questões de interpretação e outras como: "Observe as formas verbais empregadas no texto e responda: em que tempo e modo verbal elas estão? Essas formas verbais expressam fato ou opinião?" (DELMANTO; CARVALHO, 2018a, p. 179). Como expectativa de resposta, espera-se que o aluno saiba que as formas verbais empregadas no texto - no caso aqui citado, um cartaz de publicidade 
do Ministério da Saúde, sobre obesidade infantil - estão no presente do indicativo e que expressam fatos. Verificamos, portanto, que a expectativa de resposta é análoga ao que está contido na caixa explicativa sobre o presente do indicativo, ilustrado no parágrafo anterior.

Nas gramáticas normativas tradicionais ou didáticas, como a de Cipro-Neto e Infante (2003) e a de Cegalla (2001), o estudo dos verbos é dedicado à seção de morfologia, com a subdivisão em mais de um capítulo, em que são abordados conceitos como estrutura das formas verbais, flexões, tempos, modos, conjugações e formas nominais. Em algumas, há a tentativa de exemplificar os usos dos verbos em enunciados comuns nas práticas linguísticas cotidianas, como em anúncios publicitários, letras de canções, matérias de jornal. Em outras, no entanto, ainda encontramos exemplos canônicos de escritores consagrados, com registros linguísticos bem mais próximos do século XIX que dos dias atuais.

Trazemos essa observação ao texto porque acreditamos que, ao produzir um material didático, algumas escolhas acabam distanciando ainda mais o estudo da língua de seus reais usos e, consequentemente, de seus falantes, o que justifica alguns dizeres que nós, professores de Português, ouvimos, com certa frequência, de nossos alunos e das pessoas com quem convivemos, como: "português é difícil" ou "eu não sei falar direito"...

Dessa forma, cabe evidenciar, ainda, a proposta de trabalho para o componente de Língua Portuguesa, na BNCC, que

[...] assume a centralidade do texto como unidade de trabalho e as perspectivas enunciativo-discursivas na abordagem, de forma a sempre relacionar os textos a seus contextos de produção e o desenvolvimento de habilidades ao uso significativo da linguagem em atividades de leitura, escuta e produção de textos em várias mídias e semioses. (BRASIL, 2017, p. 65).

Temos, nesse excerto, de forma bastante clara, o apontamento da necessidade de um trabalho linguístico articulado às situações de produção discursivas e aos usos significativos da linguagem, o que nos possibilita pensar em materiais cada vez mais relacionados às práticas sociais de uso da linguagem, do ponto de vista da seleção de repertório e da promoção de reflexão sobre a língua.

Pensando nessa articulação linguístico-discursiva de que trata a BNCC é que propostas desarticuladas das situações reais de uso da linguagem, como mera memorização de nomenclaturas, classes ou categorias gramaticais, não devem mais ter lugar na escola. 
Antes de passarmos à próxima parte do trabalho, na qual pretendemos apresentar alguns estudos teóricos acerca do uso do presente do indicativo, trazemos alguns conceitos e atividades encontrados nos livros didáticos das coleções e gramáticas aqui citadas.

Como definição de verbo, temos, em Cegalla (2001, p. 182), a "palavra que exprime ação, estado, fato ou fenômeno". Já em Cipro-Neto e Infante (2003, p. 119),

Verbo é a palavra que se flexiona em número (singular/plural), pessoa (primeira, segunda, terceira), modo (indicativo, subjuntivo, imperativo), tempo (presente, pretérito, futuro) e voz (ativa, passiva, reflexiva). Pode indicar ação (fazer, copiar), estado (ser, ficar), fenômeno natural (chover, anoitecer), ocorrência (acontecer, suceder), desejo (aspirar, almejar) e outros processos.

É possível perceber, por essas duas definições, que conceituar o verbo a partir de suas características semânticas - embora Cipro-Neto e Infante apresentem outras características, além delas - é recorrente, tanto que, no livro didático do $6^{\circ}$ ano, encontramos a mesma definição presente em Cegalla. De acordo com llari e Basso (2008, p. 264), quem fez a primeira sistematização sobre a semântica do verbo foi Aristóteles, que "separava os verbos em três grandes categorias: 'estados', 'movimentos' e 'atividades'.". Constatamos que, de certa forma, essa noção de classificação permanece nos conceitos atuais.

A respeito do tempo verbal, uma definição comum do presente do indicativo é que "representa ações que ocorrem no momento da fala/ escrita" (CIPRO-NETO; INFANTE, 2003, p. 122) ou que ele "situa o fato ou ação verbal que ocorre durante o ato da comunicação" (CEGALLA, 2001, p. 182, grifo do autor).

A partir dessas definições, um tanto restritivas se comparadas à amplitude dos tempos gramaticais e cronológicos dos discursos, é que se formam uma cadeia de questionamentos, muitas vezes, de difícil abordagem pelo professor. Ora, se o Presente do Indicativo é um tempo verbal que representa ações simultâneas à fala/escrita, como justificar o seu uso em enunciados como: (a) Joana não fuma, (b) Se saio mais tarde, perco o ônibus ou (c) Vivemos dias difíceis. Ainda, tomando a definição de que esse tempo situa ações ocorridas durante o ato da comunicação, como explicar a construção de roteiros cinematográficos, por exemplo, que descrevem ações a serem realizadas futuramente e que, no entanto, fazem largo uso do presente do indicativo?

Para responder a essas questões, tão comuns nas práticas comunicativas atuais, mas tão pouco evidenciadas nos materiais didáticos, recorremos, no próximo tópico, ao que autores como Castilho (2019) e Vargas (2010) apontam como relação entre tempo e aspecto verbal. 


\section{Aspecto e tempo verbal: outra abordagem para o presente do indicativo}

Embora haja uma necessidade de distinção entre tempo e aspecto verbal, compartilhamos das ideias de Vargas (2010), para quem o fenômeno do aspecto verbal é estreitamente ligado à categoria de tempo. O mesmo se vê em Castilho (2019), quando afırma que é praticamente impossível descrever o tempo verbal sem considerar o aspecto, ao mesmo tempo. Isso se justifica, ainda de acordo com Vargas (2010), porque ambas as categorias se apoiam na noção de tempo.

"Tempo é uma propriedade da predicação cuja interpretação tem de ser remetida à situação de fala." (CASTILHO, 2019, p. 418). Isso significa que, tomando por base o sujeito falante, é que temos a representação da anterioridade, da simultaneidade e da posterioridade do ato de fala. Ao aspecto, relacionam-se noções como duração, instantaneidade, começo, desenvolvimento e fim, o que nos permite dizer, segundo esses dois autores, que o tempo pressupõe o aspecto.

Vargas (2010), fazendo uso de dois aspectos considerados básicos pelos gramáticos que se dedicam ao estudo do verbo, elenca o perfectivo, que exprime um fato tomado em sua completude, ou seja, um fato concluído, acabado, e o imperfectivo, que compreende as várias fases de um processo considerado em seu desenvolvimento, em sua duração e continuidade.

Levando em conta esses estudos e nossas necessidades de expressão de circunstâncias diversas, podemos admitir ao menos três situações de uso dos verbos que, de acordo com Castilho (2019), são as seguintes: a) o tempo real, quando o tempo que o falante usa coincide com o tempo cronológico; b) o tempo fictício ou metafórico, que é aquele que difere do tempo cronológico; c) o uso atemporal, que expressa um sentido vago e impreciso.

Naturalmente, essas três situações de uso acima referidas aplicam-se também ao presente do indicativo. Isso nos possibilita, então, explicar que, no exemplo (a) Joana não fuma, embora o verbo fumar esteja flexionado no presente do indicativo, temos um registro atemporal do verbo, uma vez que ele expressa uma predisposição, e não uma ação que ocorre no momento da fala, como encontrado nas definições correntes para esse tempo verbal. Em (b) Se saio mais tarde, perco o ônibus, temos um presente metafórico, utilizado no lugar do pretérito imperfeito do subjuntivo e em (c) Vivemos dias difíceis, há um presente largo ou imperfectivo, em consonância com o tempo real, representando a continuidade típica do aspecto verbal em questão. 
Julgamos que uma abordagem menos restritiva e normativa do tempo e aspecto verbal, substituída por uma mais ampla e significativa, aproximem o ensino da gramática dos falantes, levando-os a utilizar os diversos mecanismos linguísticos nos mais variados contextos discursivos.

No próximo item, apresentamos uma proposta didática para abordagem dos usos do presente do indicativo, de forma a considerar as bases teóricas aqui apresentadas.

\section{Proposta didática}

A proposta didática que apresentamos aqui pode ser desenvolvida com alunos do $7^{\circ}$ ano do ensino fundamental - anos finais, em aproximadamente, 6 aulas. 0 objetivo dessas atividades é levar o aluno a refletir sobre as diferenças entre o tempo gramatical e o tempo cronológico, em relação aos usos do presente do indicativo, na construção de textos diversos.

Na sua execução, escolhemos o gênero canção, a partir da obra "Iracema", do cantor e compositor brasileiro, Adoniran Barbosa, e uma notícia de jornal. A preferência pela canção justifica-se pelo fato de que

[...] o cancioneiro popular brasileiro é rico e variado, constituindo-se um campo de estudo muito fértil. A canção popular brasileira, mesmo sendo um gênero tão representativo da nossa cultura, ainda foi pouco estudada do ponto de vista discursivo. (CARETTA, 2009, p. 112).

O primeiro passo para o desenvolvimento da proposta de atividades é a apresentação da canção "Iracema". É imprescindível que a audição da canção seja garantida aos alunos, uma vez que, de acordo com Costa (2001), estamos trabalhando com um gênero sincrético, composto por duas linguagens, a verbal e a musical, e cujos sentidos só se dão na relação entre essas semioses. Por vezes, vemos em materiais didáticos a utilização da letra da canção, tomada como se fosse um poema, sem qualquer menção à parte musical que compõe o gênero. Nossa intenção aqui é privilegiar o estudo da canção como um todo, não apenas da letra, por isso, ouvi-la na voz do intérprete, com todos os arranjos musicais é fundamental para uma abordagem mais completa do gênero em questão. Essa abordagem indissociável entre letra e música, num primeiro momento, torna-se importante para apresentar a canção da forma em que ela circula no cotidiano. Quando ouvimos a canção, não temos a linguagem verbal e musical dissociadas, mas formando uma unidade que caracteriza o gênero.

Sabemos das limitações que o material impresso pode imprimir ao trabalho com gêneros circulados em outras mídias, como a canção, por exemplo. Nossa proposta, para 
superar essas limitações, é lançar mão da tecnologia disponível e acessível aos alunos e professores, como o celular, por exemplo. Pensando no suporte impresso, apresentamos a letra da canção acompanhada por um QR Code e um link, que possibilitam o acesso a sua audição por meio do aparelho celular. Segue nossa proposta de apresentação da canção:

Figura 1. Apresentação da canção "Iracema", de Adoniran Barbosa

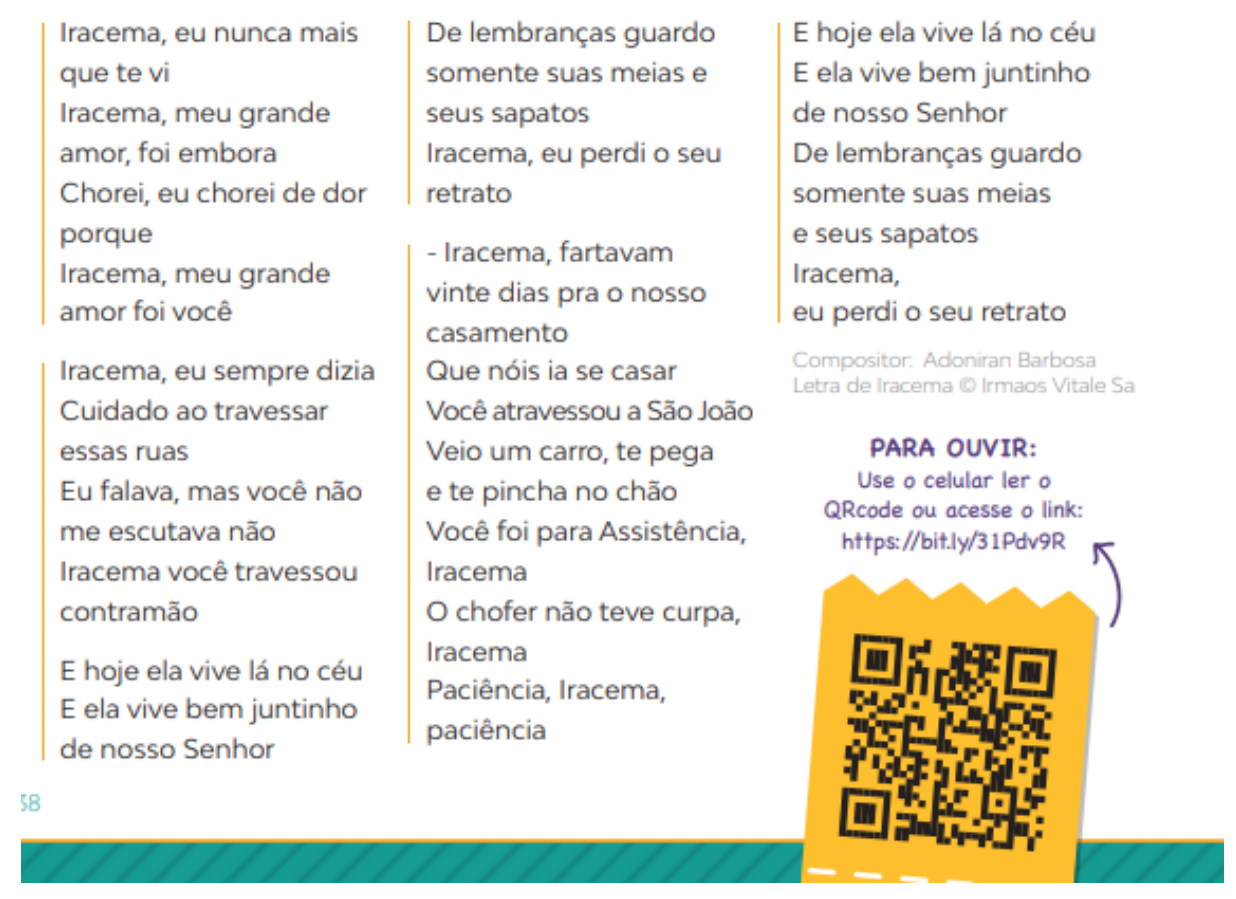

Fonte: Elaborado pela autora como trabalho acadêmico da disciplina de Gramática, Variação e Ensino, no curso de Mestrado Profissional em Letras, da Faculdade de Filosofia, Letras e Ciências Humanas da Universidade de São Paulo. Material não publicado

Após a audição da canção, é interessante conversar com os alunos sobre os sentimentos despertados pela música, sobre a temática, o tom de voz empregado pelo intérprete, se os fatos narrados pela letra relacionam-se com o acompanhamento musical, despertando alegria, tristeza ou outros sentimentos em quem está ouvindo.

Na sequência, podem ser apresentadas informações sobre o cantor e sobre o momento de produção da canção. Uma boa estratégia para esta etapa é explorar a capa e contracapa do disco de lançamento da canção, atentando-se para a data de composição e gravação da música. Em relação à "Iracema", podemos levantar os seguintes dados: a) foi composta em 1956, por Adoniran Barbosa (1910-1982); b) Adoniran ficou conhecido como o pai do samba paulista, retratando o modo de vida das pessoas, na época da expansão e modernização das cidades; c) a canção foi criada a partir de uma notícia de 
jornal, sobre um atropelamento; d) os atropelamentos eram muitos comuns nessa época, devido à reestruturação da cidade de São Paulo, com o alargamento de ruas e avenidas, fazendo parte da crescente onda de violência urbana, também retratada pelo autor; e) os acontecimentos reais, segundo o autor, deram-se na Rua Consolação, que foi substituída, na música, por Avenida São João.

Em continuidade à análise, as seguintes questões podem ser propostas:

Figura 2. Proposta de questões sobre o texto apresentado

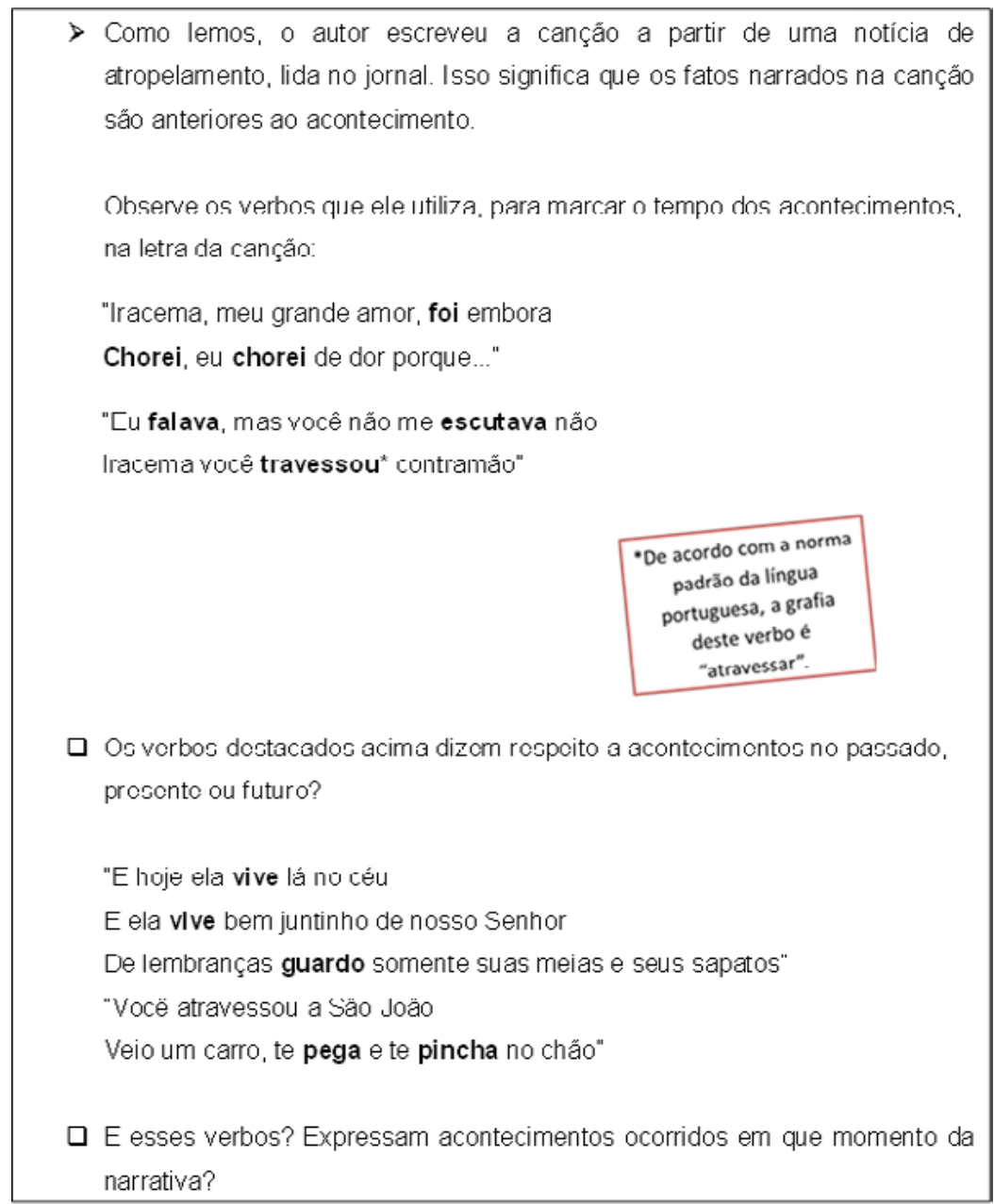

Fonte: Elaborado pela autora como trabalho acadêmico da disciplina de Gramática, Variação e Ensino, no curso de Mestrado Profissional em Letras, da Faculdade de Filosofia, Letras e

Ciências Humanas da Universidade de São Paulo. Material não publicado

A partir desse momento, podemos analisar com os alunos os versos da canção, propostos nas questões anteriores. Dessa forma, teremos que no verso "E hoje ela vive lá no céu", a forma verbal "vive" indica uma ação duradoura (o sujeito está vivendo), ocorrida em 
simultaneidade com a fala/escrita. Em "Veio um carro, te pega e te pincha no chão", as formas verbais "pega" e "pincha" estão empregadas com o sentido de ações situadas anteriormente ao momento da fala/escrita (veio um carro, te pegou e te pinchou no chão). Trata-se de um presente metafórico, bastante usado na construção de narrativas, para se referir a fatos passados, dando mais vivacidade às histórias. Já em "Qualquer dia você sai e é atropelada", as formas verbais "sai" e "é" estão empregadas com o sentido de ações situadas posteriormente ao momento da fala/escrita (qualquer dia você sairá e será atropelada). Trata-se também de um presente metafórico, utilizado para se referir ao futuro. Por fim, em "Ele é considerado um dos mais importantes sambistas do país", a forma verbal "é" indica uma verdade, sem, necessariamente, marcar um tempo. Figurase, assim, o presente atemporal, das verdades eternas, dos ditados populares.

Após a reflexão sobre os diferentes usos atrelados ao presente do indicativo, na canção de Adoniran, sugerimos apresentar uma notícia de jornal que, preferencialmente, dialogue com o tema da canção. Dessa maneira, podem ser exploradas relações intertextuais e interdiscursivas, na análise dos textos. Segue-se nossa sugestão de notícia, veiculada num jornal on-line.

Figura 3. Notícia sobre um atropelamento

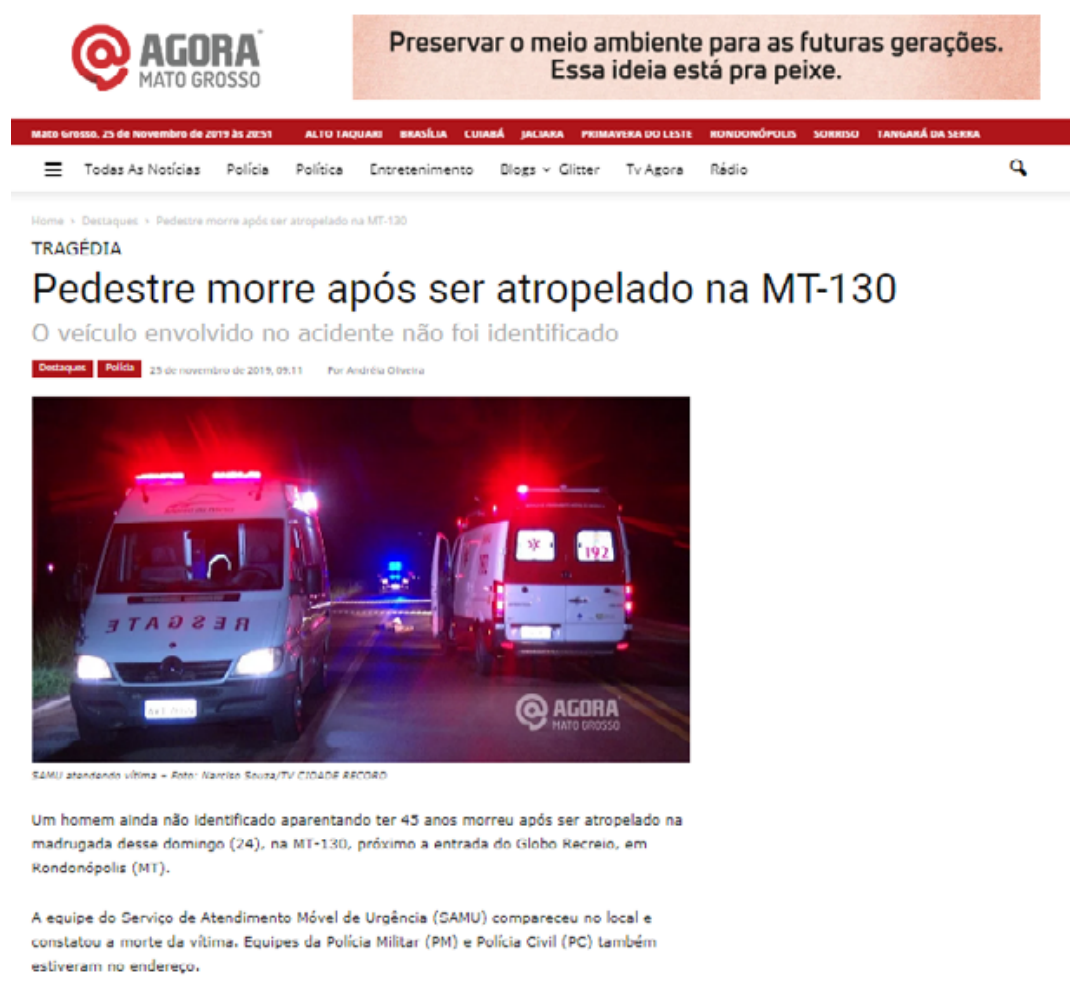

Fonte: https://www.agoramt.com.br /2019/11/pedestre-morre-apos-ser-atropelado-na-mt-130. Acesso em: 26 nov. 2019 
Figura 4. Texto da notícia, ampliado

Um homem ainda não identificado aparentando ter 45 anos morreu após ser atropelado na madrugada desse domingo (24), na MT-130, próximo a entrada do Globo Recreio, em Rondonópolis (MT).

A equipe do Serviço de Atendimento Móvel de Urgência (SAMU) compareceu no local e constatou a morte da vítima. Equipes da Polícia Militar (PM) e Polícia Civil (PC) também estiveram no endereço.

Fonte: https://www.agoramt.com.br /2019/11/pedestre-morre-apos-ser-atropelado-na-mt-130. Acesso em: 26 nov. 2019

Sobre a análise da notícia, as seguintes questões podem ser propostas: a) Quais os tempos verbais utilizados no título da notícia? b) E no corpo da notícia, quais os tempos verbais predominantes? c) Por que você acha que os autores escolhem tempos verbais diferentes para o título e o corpo do texto? d) A notícia, como a canção ouvida, trata de um atropelamento. Em ambos os textos, os autores utilizam verbos no passado e no presente, alternadamente. Há diferença de sentido em dizer: "Pedestre morre após ser atropelado" e "Pedestre morreu após ser atropelado"? Qual/quais?

Ao propormos essas questões, esperamos que os alunos identifiquem que o tempo verbal utilizado no título da notícia "Pedestre morre após ser atropelado na MT-130" é o presente do indicativo, que difere dos tempos verbais predominantes no corpo da notícia, em que prevalece o pretérito perfeito, com as formas "morreu", "compareceu", "constatou" e "estiveram". Esperamos, ainda, que eles consigam apresentar uma reflexão sobre a escolha de tempos verbais diferentes no título e no corpo da notícia, relacionando-a aos efeitos de sentido. No título, a utilização da forma verbal "morre", no presente do indicativo, está relacionada à ideia de instantaneidade, momentaneidade, característica do gênero. Já no corpo do texto, o pretérito perfeito é utilizado para se referir ao momento de ocorrência dos fatos reportados na notícia, em relação ao momento em que se escreve. Pelo uso desse tempo verbal, é possível saber que os fatos narrados ocorreram anteriormente ao momento da escrita.

Por fim, esperamos que eles sejam capazes de explicar a diferença de sentido existente entre: "Pedestre morre após ser atropelado" e "Pedestre morreu após ser atropelado", percebendo que, na primeira ocorrência, o verbo empregado no presente do indicativo relaciona-se à ideia do momento, de um fato que ocorre "agora" e, na segunda, a forma "morreu" remete a um fato passado, já ocorrido. A partir desses usos e da consideração de que o texto estudado é uma notícia, é possível perceber a intencionalidade do autor em apresentar ao leitor fatos recentes, momentâneos. 
No desenvolvimento da proposta didática, seja essa que sugerimos ou outra, éfundamental proporcionar aos alunos o contato com diferentes notícias de jornais impressos e on-line, bem como chamar a atenção para o uso corrente do presente do indicativo nos títulos das notícias. Oferecer uma variação nos tamanhos dos textos também é bastante desejável, pois ao apresentar notícias com diferentes extensões textuais é possível explorar mais formas verbais. Sobre a necessidade de trabalho com a diversidade de textos, temos a seguinte constatação:

Ao inserirmos a diversidade de gêneros nas práticas didáticas, colocamos o aluno em contato com gêneros textuais que são produzidos fora da escola, em diferentes áreas de conhecimento, para que ele reconheça as particularidades do maior número possível deles, e possa preparar-se para usá-los de modo competente quando estiver em espaços sociais não escolares. (SANTOS; SILVEIRA, 2021, n.p.).

Em suma, permitindo o contato com uma variedade de textos é que os estudantes poderão estabelecer relações entre os textos e perceber os padrões de escrita que se repetem nos mesmos gêneros, podendo fazer uso deles, com proficiência.

\section{Considerações finais}

Ao escrever o presente artigo, sobre os usos do presente do indicativo, levando em conta alguns estudos sobre o aspecto e tempo verbal, pudemos analisar algumas produções didáticas que estão longe de contemplar um uso significativo da linguagem, como requerem, já há algumas décadas, os documentos oficiais norteadores do ensino.

A intenção de elaborar e trazer uma proposta didática, aqui, foi promover a aproximação entre os estudos acadêmicos e as bases teóricas com as práticas de sala de aula. Dessa forma, foi possível perceber a necessidade de viabilizar tempo e condições de estudo ao professor, para que ele possa se dedicar à seleção, ou mesmo elaboração, de materiais didáticos mais relevantes aos seus alunos.

Por fim, acreditamos, com essa abordagem dos usos do presente do indicativo, aproximar o estudo dos tempos verbais às situações reais de uso, fugindo de um tratamento mecânico e distanciado da linguagem, no cotidiano, que, muitas vezes, está presente nas gramáticas tradicionais e livros didáticos.

\section{REFERÊNCIAS}

BARBOSA, A. Letras. Disponível em: https://www.letras.mus.br/adoniran-barbosa/ Acesso em: 25 maio 2019.

BRASIL. Base Nacional Comum Curricular (BNCC). Brasília, MEC/CONSED/UNDIME, 2017. Disponível em: www.basenacional comum.mec.gov.br/. Acesso em: 31 mar. 2019. 
CARETTA, A. A. A canção popular: uma análise discursiva. In: GIL, B. D.; CARDOSO, E. de A.; CONDÉ, V. G. (org.). Modelos de análise linguística. São Paulo: Contexto, 2009. p. 99-114.

CASTILHO, A. T. de. Nova gramática do português brasileiro. São Paulo: Contexto, 2019. p. $416-433$.

CEGALLA, D. P. Novíssima gramática da língua portuguesa. 44. ed. São Paulo: Companhia Editora Nacional, 2001.

CIPRO-NETO, P.; INFANTE, U. Gramática da língua portuguesa. São Paulo: Scipione, 2003.

COSTA, N. B. da. A produção do discurso lítero-musical brasileiro. 2001. Tese (Doutorado em Linguística Aplicada) - Pontifícia Universidade Católica de São Paulo, São Paulo, 2001.

DELMANTO, D.; CARVALHO, L. B. de. Português: conexão e uso. $6^{\circ}$ ano. São Paulo: Saraiva, $2018 \mathrm{a}$.

DELMANTO, D.; CARVAlHO, L. B. Português: conexão e uso. $7^{\circ}$ ano. São Paulo: Saraiva, 2018b.

FIGUEIREDO, L.; BALTHASAR, M.; GOULART, S. Singular e plural. $7^{\circ}$ ano. São Paulo: Moderna, 2019.

ILARI, R.; BASSO, R. M. Classes de palavras e processos de construção. 3. O verbo. In: NEVES, M. H. de M.; ILARI, R. (org.). Gramática do Português Falado Culto no Brasil. v. II Campinas: Editora da UNICAMP, 2008.

OLIVEIRA, A. Pedestre morre ao ser atropelado na MT-130. Agora Mato Grosso. Mato Grosso, 25 nov. 2019. Disponível em: https://www.agoramt.com.br /2019/11/pedestremorre-apos-ser-atropelado-na-mt-130/. Acesso em: 26 nov. 2019.

SANTOS, H. A. dos; SILVEIRA, S. P. B. B. da. A importância da utilização do texto e a articulação entre as áreas de conhecimento. Disponível em: https://educador.brasilescola.uol.com.br/ trabalho-docente/importancia-texto-articulacao-areas-conhecimento.htm. Acesso em: 1 fev. 2021.

VARGAS, M. V. O ensino do verbo: tempo e aspecto como categorias semânticodiscursivas. Linha D'Água, n. esp., p. 119-131, 27 set. 2010. Disponível em: https://doi. org/10.11606/issn.2236-4242.v0ispep. Acesso em: 13 dez. 2019. 